\title{
HENRIQUE C. DE L. VAZ, S. J., LEITOR DE EMMANUEL MOUNIER
}

\author{
Henrique C. de L. Vaz, S.J., a reader of Emmanuel Mounier
}

Maria da Penha Villela-Petit *

Resumo: Nesse artigo, faço um breve apanhado de como se deu meu conhecimento do pensamento de Mounier e do que esse conhecimento deve ao Pe.Vaz, desde de meus anos na PUC do Rio de Janeiro (entre 1958 e 1962). Ficara desde então sabendo o quanto Pe. Vaz apreciava o personalismo Mounier no que se refere à necessidade imperativa para um cristão de não dissociar o pensamento do agir, de não separar sua fé e sua frequência à igreja de um empenho efetivo em vista de uma maior justiça social. Mounier havia justamente aprofundado a noção de engajamento. Procurei mostrar também como a reflexão de Mounier fôra marcada por um autor de origem alemã, que se tornara francês, que escrevera sobre o "engajamento ». A admiração do Pe Vaz por Mounier foi muitas vêzes objeto de meus "Témoingnages», em francês, a respeito do pensamento personalista de um dos maiores filósofos brasileiros, senão o maior, ou seja o Pe Vaz. No final do artigo aponto radidamente como nos dias de hoje devemos levar adiante a reflexão sobre a tecno-ciência e seus possíveis malefícios para a Terra e a humanidade.

Palavres-chaves: Mounier. Personalismo. Fé e ação presente. Engajamento.

Abstract: In this article, I make a brief overview of how I came to know Mounier's thinking and what I owe to Fr.Vaz in this respect, since my years at PUC, Rio de Janeiro (between 1958 and 1962). Fr. Vaz appreciated Mounier's personalism

\footnotetext{
* Pesquisadora aposentada dos Archives Husserl do Centre National de la Recherche Scientifique (CNRS) e professora aposentada do Institut Catholique de Paris, França. Faz parta da Association des Amis d'Emmanuel Mounier. Artigo recebido em 12/09/2020 e aprovado para publicação em 13/12/2020.
} 
regarding the imperative need for a Christian not to dissociate thinking from acting and separate faith and attendance at church from an effective commitment to greater social justice, a notion that Mounier had just developed. I also show that Mounier's reflection was marked by an author of German descent, a naturalized French citizen, who had written about "engagement". Fr Vaz's admiration for Mounier has often been mentioned in my "Témoignages", written in French, in which I refer to the personalist thought of one of the greatest Brazilian philosophers ever, if not the greatest, that is, Henrique Cláudio Lima Vaz. In the last part of this paper, I briefly discuss how we must further our present reflection on technoscience and its potential harms to both the Earth and humanity.

Keywords: Mounier. "Personalist" philosophy. Faith and action. Commitment.

$\mathrm{E}$ m 2020, celebra-se os 70 anos do falecimento precoce (em março de 1950), de Emmanuel Mounier quando, poucos dias depois, ele completaria apenas 45 anos. Ele havia fundado em outubro de 1932, a revista Esprit que existe até hoje e que se tornara bastante conhecida já em 1934. Foi na época em que eu estudava na PUC (entre 1958 e 1962), - e preocupada com a injustiça social que predominava no nosso país -, é que passei a ler alguns dos textos de E. Mounier e também artigos de alguns autores dos movimentos católicos brasileiros que dele se inspiravam.

Em 2005, isto é, no ano em que se celebrava o centenário de seu nascimento, que ocorrera em 1905, ano que fôra também o do nascimento de Jean-Paul Sartre e o de Raymond Aron, a Síntese publicou um artigo meu com o título de «Emmanuel Mounier: um pensamento em ação». ${ }^{1}$

Anteriormente, em dois livros publicados pela Association des Amis d'Emmanuel Mounier, eu havia apresentado dois «testemunhos» da presença do pensamento de Mounier no Brasil, pois fôra aqui no nosso país que eu tomara conhecimento de Mounier e da revista Esprit. O primeiro desses «témoignages» figura na coletânia intitulada Le Personnalisme d'Emmanuel Mounier-hier et demain [Pour un cinquantenaire]». Volume que reune as exposições feitas pelos participantes do Colóquio ${ }^{2}$ comemorando os 50 anos da revista.

Nesse artigo «Témoignage (Brésil)», ${ }^{3}$ depois de uma breve alusão ao Centro Dom Vital e a Jacques Maritain, eu me apoio sobre o que havia sido escrito, de maneira muito significativa em 1976 pelo Pe Henrique Cláudio de Lima Vaz S.J. na sua Bio-Bibliografia, cujo texto foi reproduzido no

\footnotetext{
${ }^{1}$ Cf., Síntese, vol. 32, n ${ }^{\circ} 103$ (maio/agosto 2005) p. 149-167.

${ }^{2}$ Colóquio realizado de 30 de outubro ao $1^{\circ}$ de novembro 1982 e cuja edição pelas éd. du Seuil data de 1985, com uma bela «Ouverture » de Paulette Mounier.

${ }^{3}$ Cf. Maria da Penha VILLELA-PETIT, «Témoignage (Brésil) », in op. cit., p. 177-179.
} 
volume Cristianismo e História, volume coletivo coordenado por Carlos Palácio em homenagem aos 60 anos de Pe. Vaz.

Evidentemente, no meu « Témoignage » que se encontra no livro Le Personnalisme d'Emmanuel Mounier- hier et demain, eu havia traduzido em francês parte da passagem do Pe. Vaz, que agora vou citar no original, em português.

Ao mencionar justamente o que tinha sido seu primeiro artigo, artigo sobre «O existencialismo», que o Pe. Franca aceitara publicar na revista Verbum em março de 1948, Pe. Vaz escreve:

«Posso dizer que dessa crítica ao existencialismo de tipo sartreano nunca voltei atrás, não obstante o profundo choque intelectual que a obra de Sartre causou em todos nós naqueles anos do após-guerra em que tudo se questionava, tudo se julgava possível, mas sobre os quais pairava o obscuro pressentimento de um novo ciclo de crises mais profundas e mais decisivas. Sobre as dimensões e as dimensões dessas crises que se anunciavam falava-nos a obra de E. Mounier, outra descoberta capital desses anos, e a leitura, mês após mês da revista Esprit, que nos oferecia um fio condutor na complexidade do universo social e político. O personalismo foi, para mim, o primeiro instrumento de leitura do mundo moderno nos seus aspectos politicos e sociais, que nossa formação escolástica desconhecera soberanamente (o próprio Pe. Lustosa, não obstante sua aguda sensiblidade histórica, ficara preso à miragem de um corporativismo anacrônico, que seduzira os «católicos sociais» entre a «Rerum Novarum» e a «Quadragesimo Anno») e que a obra do Maritain dos anos anos 30 começara a revelar-nos.» ${ }^{4}$

Comentarei mais adiante o que manifestava essa passagem do Pe Vaz e outras semelhantes. Mas como fiz alusão aos meus dois "Témoignages » sobre o pensamento de Mounier, ambos relativos a sua presença no Brasil, vou agora mencionar o segundo antes de voltar ao Pe. Vaz .

Esse meu segundo «Témoignage » consta de um Volume intitulado Refaire la Renaissance- Hommage à Emmanuel Mounier ; homenagem que ocorreu no ano de 1990 por ocasião dos 40 anos da morte de Mounier. Ela (essa homenagem) aconteceu por iniciativa das autoridades da cidadezinha de Châtenay-Malabry. Foi lá nesse subúrbio de Paris que Mounier havia criado a residência "Les Murs-Blancs », onde, além dele e de sua família, habitavam outros intelectuais, como Henri-Iréné Marrou, Paul Fraisse, Jean-Marie Domenach etc.. ${ }^{5}$

\footnotetext{
${ }^{4}$ Cf. Pe. H.C. de LIMA VAZ, "Bio-bliografia ", in Cristianismo e História, coletânea cujo coordenador foi Carlos Palácio, Edições Loyola, 1982, p. 418-419.

${ }^{5}$ No terreno da residência chamada Les Murs Blancs havia duas casas de três andares cada uma e ainda um pequena casa perto da entrada, que passou a ser um lugar onde se reunia a associação Mounier, e, no andar de cima, havia parte de biblioteca de Mounier; em cada andar dos dois imóveis de três andares habitava uma das famílias que se associaram a Mounier e a seu projeto.
} 
Importa acrescentar que alguns anos depois do falecimento de Mounier, Paul Ricœur foi também morar nos Murs Blancs, o que manifestava sua admiração pelo projeto de Mounier de partilhar uma residência onde a inter-relação dos residentes confereria à vizinhança um sentido outro que apenas local, ou seja um sentido inter-pessoal, comunitário.

Quanto ao encontro sobre La Pensée d'Emmamunel Mounier aujourd'hui en Europe et en Amérique Latine, ele se passou sob a forma d'Entretiens (de Entrevistas) de alguns participantes em torno de uma Mesa Redonda (Table Ronde). O livro em questão, além dos Entretiens dos que haviam sido solicitados, foi completado por algumas fotos e por uma seleção de escritos da revista Esprit. Escritos que vão de 1932, ano da fundação da revista Esprit, até 1950, data do falecimento de Mounier. Embora a maioria desses textos sobre "O existencialismo », tivessem sido escritos pelo próprio Mounier, há também alguns escritos de outros colaboradores da revista.

Antes de prosseguir gostaria de lembrar que para realizar a revista Esprit, o que exigia um imenso trabalho, Mounier tivera que renunciar a seu posto de professor do Estado francês, embora tivesse passado o concurso da agregação com grande sucesso pois tirara o segundo lugar, sendo apenas precedido por Raymond Aron. Tal renúncia lhe deixara, de fato, com pouquíssimos recursos financeiros. Ele e sua família foram ajudados por amigos e, dentre eles, alguns que adeririam ao projeto de Mounier de criar relações comunitárias inovantes, e que seriam os futuros residentes des Murs Blancs.

Por outro lado, a realização de Esprit que absorvia o tempo de Mounier, se não lhe impedia de ler com muita atenção o que mais contava para as suas tomadas de posição e a redação de seus artigos para a revista (e de seus livros), não lhe permitia levar adiante outras leituras que não estivessem diretamente ligadas ao seu pensamento personalista e a sua vida espiritual. Entrevê-se aí como a cultura filosófica do Pe. Vaz, que devorava livros de filosofia e de teologia em várias línguas, só podia ter sido mais extensa e rica que a de Mounier, que, além do mais, morreu tão cedo, isto é com apenas 45 anos.

Ambos, no entanto, tinham em comum uma verdadeira vocação filosófica e sobretudo não queriam separar o trabalho intelectual - que efetuavam no horizonte da fé e da espiritualidade cristã - da promoção de mais justiça no nosso mundo. Um mundo tão afetado pelas diferenças sociais e pelo individualismo dominante no Ocidente, ou pelo materialismo comunista que se impusera depois da revolução na União Soviética.

No meu testemunho, quando na « Entrevista » (Entretien) a qual me referi, fui interrogada na Table-Ronde, por Jean Offredo («Être personnaliste aujourd'hui, pour vous, qu'est-ce que cela signifie ?»), preferi não me concentrar sobre a minha pessoa mas evocar o Colóquio que, justamente, 
em agosto de 1990 se passara em São Paulo sobre Mounier, Teilhard de Chardin e Padre Lebret. Colóquio que contou com a presença de Madame Paulette Mounier. Na minha evocação procurei chamar atenção para uma recordação, que, em suas Memórias improvisadas, Alceu Amoroso Lima (que assinava seus artigos jornalísticos como 'Tristão de Athayde'), havia escrito sobre sua visita a Mounier em Châtenay-Malabry. Essa visita ocorrera em janeiro de 1950, menos de dois meses, portanto, antes da morte imprevista do diretor d'Esprit.

A esse respeito, Alceu Amoroso Lima escrevera : «Guardo uma lembrança inesquecível desse encontro, eu já conhecia sua obra e o trabalho que ele desenvolvia em meio a numerosas dificuldades, mas, hoje, sinto-me mais próximo dele em matéria social que de Maritain que, depois de seu livro, L'humanisme intégral, virou praticamente as costas a tais problemas». ${ }^{6}$

Essa confissão de A. Amoroso Lima é por si só'bastante significativa da influência que Mounier passara a exercer no Brasil sobretudo nos meios católicos.

Sobre Refaire la Renaissance-Hommage à Emmanuel Mounier, vale ainda lembrar que o último texto que nele figura aborda justamente "La Mort d'Emmanuel Mounier » (em março 1950), texto publicado no $\mathrm{n}^{\circ}$ de maio de 1950 da revista Esprit. Ora, poucas páginas antes, lê-se justamente a reprodução do texto de Mounier sobre a morte cruel de seu amigo PaulLouis Landsberg, colaborador d'Esprit.

Católico ardente, o alemão Paul-Louis (Ludwig) Landsberg, que era de origem judia e que, depois de ter morado algum tempo na Espanha, passara a viver na França (reclamando aliás a nacionalidade francesa, que acaba obtendo) fôra apanhado pelos nazistas e enviado a Drancy, e, em seguida, ao campo de Oranienburg onde morreu.

Recordar Paul-Louis Landsberg, a respeito do pensamento personalista de Mounier e da necessidade de um engajamento é essencial quando se compreende que fé e vida cristã não podem ser dissociadas. No seu artigo «Paul-Louis Landsberg», publicado no ${ }^{\circ}$ de janeiro de 1946, depois de confirmada a morte de Landsberg, Mounier escrevera:

«A perda não é menor para o pensamento e para a ação de inspiração personalista. Ele foi, e será para sempre, pelo que nos deu, uma das pedras angulares de Esprit. Ninguém mais do que ele contribuiu por volta de 1935 à nos livrar das tentações utópicas, a nos inocular, antes que a palavra estivesse na moda, o que era necessário de existencialimo para

${ }^{6}$ A minha citação dessa passagem de Alceu Amoroso Lima encontra-se na página 16 de Refaire la Renaissance-Hommage à Emmanuel Mounier. 
nos afastar de palavrórios abstratos. Suas « Remarques sur l'action », suas « Réflexions sur l'engagement » marcam datas cruciais na nossa história.» ${ }^{7}$

Sobre a morte (em abril de 1944) e o pensamento de P.-L. Landsberg, Paul Ricœur escreveu artigos (para Esprit), artigos que foram re-publicados em Lectures 2-La contrée des philosophes. ${ }^{8}$

Vários textos de Paul-Louis Landsberg- alguns escritos diretamente em francês e outros traduzidos do alemão-, foram reunidos num volume tendo como título «Les problèmes du personnalisme», publicado em 1952. ${ }^{9}$ Recentemente alguns dos textos dessa coletânea foram publicados separadamente em livrinhos, como é o caso de suas «Réflexions sur l'engagement personnel.» ${ }^{10} \mathrm{Na}$ capa de trás do livrinho, destaca-se uma frase de Landsberg: "Não se pode conhecer valores sem a eles se dar.»

Essa frase anuncia brevemente o que me parece muito importante no que Landsberg deu a pensar sobre a necessidade de um engajamento na história, para não se cair num intelectualismo abstrato, sobretudo quando se é cristão.

E isso decorre também de seu pensamento sobre a pessoa, e contra o individualismo do sujeito pensante ; individualismo que se instarou na modernidade e que se prolonga, diversamente, nos dias de hoje...

Um dos temas decisivos do personalismo tem a ver com a impossibilidade de se pensar a «pessoa » sem relacioná-la a «outrem» e ao outro em geral. Um ser humano, enquanto sujeito pensante, não é solipsista, não pode existir sem um outro. Mesmo um religioso eremita está relacionado com o Outro, o outro aqui sendo Deus e também aquilo que ele lê, inclusive na Bíblia, e que foi escrito por outros que lhe «falam », o interpelam...

A pluralidade dos pronomes pessoais está essencialmente ligada ao fato essencial da corporeidade do sujeito humano. $\mathrm{O}$ « eu »é corpo e alma. Nosso corpo é um corpo vivo, e não apenas matéria, como no dualismo cartesiano. A respeito do «eu», do «ego», P.-L. Landsberg ${ }^{11}$ cita esta bela afirmação (anti-cartesiana) de Maine de Biran:

«Le 'je' n'est pas la substance abstraite, qui a pour attribut la pensée, mais l'individu complet, dont le corps est une partie essentielle constituante.» ${ }^{12}$

\footnotetext{
${ }^{7}$ Cf. E. MOUNIER in Refaire la Renaissance, Hommage à Emmanuel Mounier, p. $126 \mathrm{~s}$.

${ }^{8}$ Cf. Paul RICCEUR, Lectures 2- La contrée des philosophes, Éd. du Seuil, 1992.

${ }^{9}$ Cf. Paul-Louis LANDSBERG, Problèmes do personnalisme, Préface de Jean Lacroix, coll. «Esprit », Éditions d Seuil, 1952. Os textos escritos em francês pelo autor tinham sido revistos para essa publicação.

${ }^{10}$ Paul-Louis LANDSBERG, Réflexions sur l'engagement personnel, Éditions Allia, 2018.

${ }^{11}$ Convem lembrar que P.-L. Landsberg foi discípulo de Max Sheler, pensador muito apreciado do Pe Vaz.

${ }^{12}$ Cf. Paul-Louis LANDSBERG, «Le sens de l'action » in Problèmes du Personnalisme, op.cit., p.108.
} 
Em outras palavras o 'eu' humano é um eu incarnado. Essa citação de Maine de Biran, feita num ensaio cujo título é "Le sens de l'action », nos leva a pensar mais profundamente as implicações da nossa corporeidade, como constitutiva do tempo e do espaço que vivenciamos, e portanto da nossa existência histórica.

Em se tratando de Paul-Louis Landsberg, eu acrescentaria que, poucos meses antes do início da segunda guerra mundial, num relatório que fizera com vistas a uma filosofia da guerra e da paz, ele cita rapidamente, numa nota sobre o racismo que predominava no regime nazista, parte de uma frase de Mein Kampf de Hitler. Eis o trecho em questão:

«.... uma concepção do mundo que combatendo a idéia democrática quer dar a terra ao povo superior.» ${ }^{13}$

Não posso comentar sobre o que Hitler entende aqui por 'idéia democrática', quando o regime que dela se reclama resulta de uma maioria de votos nas eleições de um país. Uma reflexão atual sobre as democracias não poderia deixar de analisar os meios publicitários de que se dispõe hoje em dia, e onde proliferam " fake news ». Isso seria um outro assunto.

Voltemos portanto ao nosso tema, isto é a presença de E. Mounier no pensamento de Pe. Vaz. ${ }^{14}$ Mounier o encorajava a agir enquanto cristão pois Pe. Vaz aspirava a mais justiça social, e isso, em sintonia com um verdadeiro amor de Deus e do próximo.

No capítulo X, do seu livro Ontologia e história, cuja primeira edição data de 1968 - capítulo cujo título é « Nota histórica sobre o problema filosófico do "outro" ", - depois de haver mencionado vários autores como Maurice Nédoncelle, dentre a corrente personalista francesa, Pe. Vaz escreve:

«Mas é o pensamento de Emmanuel Mounier que dá sua verdadeira dimensão ao personalismo francês. De procedência clássica e mesmo tomista (mas com a influência de Péguy exercendo-se fortemente em suas origens), a reflexão de Mounier orienta-se sempre mais nitidamente no sentido de vincular a afirmação da pessoa ao social e ao histórico, a situá-la, assim, no terreno concreto da relação com o outro, da dialética do nós. Por outro lado, Mounier submete o personalismo à prova da ação política. A reflexão sobre a conjuntura do "entre as duas guerras », sobre a experiência a um tempo dramática e iluminadora da "resistência a um

${ }^{13}$ Cf. Paul-Louis LANDSBERG « Réflexions pour une philosophie de la guerre et de la paix ", in Problèmes du Personnalisme, op.cit., nota 9, p. 156-157. Haveria muito o que comentar sobre essa curta mas muito significativa citação, que talvez hoje assuma formas diferentes da do nazismo, que pretendia retirar não somente a terra, mas a vida mesma dos judeus considerados inferiores à raça alemã.

${ }^{14}$ Pe. Vaz, segundo me parece, não teve oportunidade de encontrar os escritos de Landsberg. 
segundo conflito mundial", sobre a formidável polarização ideológica que marcou os primeiros anos do pós-guerra (ele morreu em 1950) impeliu poderosamente o personalismo de Mounier na direção de uma visão da história onde pessoa e comunidade se mostram como os polos dinâmicos capazes de orientar num sentido autenticamente humano a grande mutação histórica dos nosso dias, que é a planetarização do homem, oscilando, no capitalismo e no comunismo, entre o materialismo do indivíduo e o materialismo da massa. $\mathrm{O}$ encontro com o existencialismo do pós-guerra e um diálogo permanente e sempre mais empenhativo com o marxismo influíram decisivamente na última fase do pensamento de Mounier, que um desaparecimento prematuro veio abruptamente interromper."15

Quando Pe. Vaz escrevia assim sobre Mounier o mundo vivia, depois da segunda guerra mundial, o conflito entre os dois blocos: o bloco capitalista e o bloco comunista. Foi o que o próprio Mounier, que vai morrer em 1950, conheceu no após-guerra. As análises que o mundo de hoje requer seriam de certo modo diferentes e exigiriam situações e dados que não poderiam ter sido previstos.

Por outro lado Pe. Vaz que, pouco antes da passagem que acabamos de citar, havia feito alusão a Martin Buber, que havia refletido sobre o diálogo (cf. «A vida em diálogo»), e portanto sobre a relação « eu » e « tu » - reflexão que ele muito admirava - fizera também uma breve alusão ao pensador alemão Max Scheler. Max Scheler que, na verdade, não havia influenciado diretamente Mounier, mas, sim, Paul-Louis Landsberg, cujo impacto sobre o pensamento de Mounier sobre a pessoa tinha sido incontestável. Quem o sublinhou, foi justamente um outro pensador francês, Paul Ricœur, também admirador de Mounier, e que também marcou o pensamento de Pe. Vaz sobre a História.

De toda essa reflexão importa que conservemos aquilo que não cessará de interpelar o Pe. Vaz sua vida afora ; isto é a necessidade de se associar a fé e o agir cristão ; um agir que não pode dissociar o 'eu' do 'outro', ou seja do que chamamos o "próximo», e implicando em princípio que qualquer outro "ser humano » seja " um próximo ».

Uma dimensão essencial ligada ao que acabamos de dizer é a questão da pessoa, sobre a qual reflexão do Pe. Vaz é de primeira importância. No seu livro Antropologia Filosófica II, a Terceira seção- que trata da "Unidade Fundamental do Ser humano" tem um capítulo II onde ele aborda a "Categoria da Pessoa ». Nesse capítulo ele não se estende sobre o Personalismo de Mounier, mas analisa a noção de pessoa tanto filosoficamente quanto teologicamente, pois se trata de uma noção central no cristianismo. Ele começa fazendo um apanhado sobre a história complexa da noção de pessoa, o que hoje é quase

${ }^{15}$ Cf. Pe. Henrique C. de LIMA VAZ, Ontologia e História. A primeira edição que data de 1968 fôra publicada em São Paulo pela Editora Duas Cidades . Nós citamos a partir da segunda edição, isto é pelas Edições Loyola, col. Filosofia, 2001, p. 239-240. 
sempre ignorado. Eu apreciei muito essa introdução do Pe. Vaz a seu capítulo sobre a "categoria de pessoa". No latim, 'pessoa' tinha primeiro a ver com personagem, com a representação social de seres humanos. Daí a razão pela qual Pe Vaz inicia o capítulo em questão por essa frase:

“Entre todas as noções que vieram a constituir o repertório conceptual básico da Antropologia Filosófica, a noção de pessoa é, provavelmente, aquela que representa antecedents históricos mais complexos. Com efeito, antes de tornar-se um dos termos-chave do vocabulário filosófico, o termo pessoa (prósopon, persona) percorreu diversos territórios semânticos, desde a linguagem teatral, onde provavelmente reside sua origem, passando pela linguagem das profissões, pela gramática, pela retórica, pela linguagem jurídica, pela linguagem teológica, até vir a fixar-se na linguagem filosófica.»»

Essa consideração do Pe. Vaz tem muito a ver com o que num texto meu sobre Mounier, que faz parte do volume dos Actes du Colloque tenu à l'UNESCO (de 5 a 6 de outubro, 2000)- baseando-me nos escritos de Simone Weil-, eu havia lembrado sobre a ambivalência inicial da noção de pessoa, tanto em grego, prósopon, quanto em latim, persona.

Depois de desenvolver os argumentos de S. Weil, que, apesar de divergência sobre a noção de pessoa, apreciava Mounier, eu fazia alusão ao fato que os teólogos ortodoxos para designar as pessoas da Santíssima Trintade preferiam evitar o termo de prósopon e recorrer de preferência ao termo de hupostasis.

Disso S. Weil não tivera conhecimento, como também no mundo católico quase ninguém o tinha. Eu ficara sabendo, mais recentemente, graças a leitura do livro À l'image et à la ressemblance de Dieu do teólogo russo Vladimir Lossky. (Vladimir Lossky que fugira do regime soviético e tornara-se francês.)

Eis o que ele escreve sobre os « Pais Gregos » (os pais da teologia), no livro que acabo de mencionar e que eu havia citado no meu artigo sobre Mounier:

[Eles] « preferiram ao termo de prósopon, o de hupostasis para designar as pessoas divinas. » E Lossky acrescenta: "Foi um achado terminológico o fato de introduzir uma distinção entre dois sinônimos (hupostasis e ousia), para exprimir o caráter irredutivel da hypostásis à l'ousia, da pessoa à essência, sem no entanto as opor como duas realidades diferentes.» ${ }^{17}$

Para mim um outro ponto essencial era o uso negativo da palavra prósopon na Epístola de São Tiago $(2,1)$.

\footnotetext{
${ }^{16}$ Cf. Pe. Henrique de LIMA VAZ, "Categoria de Pessoa » in Antropologia Filosófica II, Ed. Loyola, 1992, p. 189.

${ }^{17}$ Ver Vladimir LOSSKY, À l'image et à la ressemblance de Dieu, éd. Aubier-Montaigne, 1967, p. 110. Mas para o Pe. Vaz, segundo o grego, «hypóstasis» designa o indivíduo, como ele menciona no capítulo V ("Pessoa e Sociedade: O Ensinamento de João XXIII" em Escritos de Filosofia- Problemas de Fronteira, Edições Loyola,1986, p. 106.
} 
No início da segunda passagem de epístola pode se ler:

«Meus irmãos, não misturem considerações de pessoas com a fé em nosso Senhor (de glória) Jesus Cristo glorificado.»

Várias traduções foram dadas a essa passagem. Mas o que pouco retém a atenção e se comenta é o fato que na Epístola, a palavra "prósopon» é usada no sentido de "personalidade ", de "personagem " para designar aqueles que aparecem por terem meios e/ ou funções sociais importantes.

Ora, quando ele aborda a categoria de pessoa, em particular na segundo volume de sua Antropologia Filosófica, Pe. Vaz nos oferece um apanhado excelente que nos permite compreender a transformação histórica decisiva que sofreu a noção de pessoa (persona em latim ou prósopon em grego) graças ao cristianismo e à Igreja católica, quando nos referimos à Trindade, às três Pessoas divinas.

Na Terceira Seção- “Unidade fundamental do ser humano", quando aborda em II a "Categoria da pessoa", ele escreve:

"A influência do paradigma fenomenológico é visível, por outro lado, em pensadores oriundos de tradições diferentes, mas que podem ser reunidos sob a denominação de 'filósofos da pessoa'. O traço comum que une esses filósofos é a reflexão crítica sobre uma civilização como a nossa sacudida por conflitos abertos ou latentes entre os grandes sistemas organizacionais da sociedade (tecnociência, economia, política, comunicação de massa, promoção histórica da pessoa." ${ }^{18}$ Numa nota (n. 58), ele vai então mencionar uma série de filósofos, dentre os quais E. Mounier.

O que importa compreender é que no horizonte dessa filosofia a pessoa não pode se vista como uma subjetividade isolada. A pessoa no seu íntimo está em contacto com outro (outra pessoa) e é a partir dessa relação que ela pensa, inclusive sobre si-mesma, sobre o sentido que procura dar a sua vida. Isso supõe uma atenção ao mundo que é o da sua vida e da comunidade a que pertence.

Nesse contexto se inscreve não somente uma dimensão digamos histórica, mas sobretudo, em se tratando de um cristão, um engajamento em favor de mais justiça, isto é do bem que devemos aos outros, quaisquer que sejam as comunidades a que eles estão ligados.

O que Pe. Vaz, influenciado por E. Mounier, cedo compreendeu é que um cristão não pode se contentar de " aderir a sua religião », frequentar seus ritos, suas celebrações. Um cristão precisa assumir uma atitude existencial que testemunhe do seu amor real ao Cristo, mesmo que isso implique sacrifícios, renúncias.

${ }^{18}$ Cf. Pe. Henrique de LIMA VAZ, in Antropologia Filosófica II, Edições Loyola, 1992, p. 184. A nota 58 se encontra na p. 242. 
A esse respeito, o testemunho dado pela existência cristã do Pe. Vaz foi admirável. Mas voltemos as suas análises do personalismo cristão e de sua necessária consciência histórica. Pe. Vaz é bastante consciente de como a Modernidade se secularizou afastando-se do cristianismo. $\mathrm{O}$ que ele vê, no entanto, no personalismo é a volta a uma comprensão inspirada pela leitura bíblica da história.

De certo modo, ele distingue a historiografia grega da hermenêutica bíblica, a qual dará origem a uma filosofia da história. Nos seus Escritos de Filosofia- Problemas de Fronteira, forma também o voto de uma antropologia cristã, antropologia que ele próprio desenvolve em sua obra filosófica.

Eis o que escreve levando em conta o que nosso tempo histórico (tanto científico quanto filosófico) requer:

«Será necessário que se verifique em pensadores cristãos poderosamente originais a experiência de realidades especificamente modernas, para que se descubram as verdadeiras dimensões de uma antropologia cristã para o nosso tempo : assim a descoberta científica em Teilhard de Chardin e a ação social e política em Emmanuel Mounier.» ${ }^{19}$

Tendo morrido em 1950 Mounier só havia conhecido de Teilhard alguns artigos publicados na revista Études dos jesuítas franceses, mas ele o admirou bastante por colocar em dia " a interpretação cristã da idéia de evolução ». E poucas linhas depois dessa referência, no seu livro La Petite Peur du XXème Siècle, Mounier acrescentava: «L'apport central du P. Teillhard, dans des rares fragments qu'il nous a jusqu'ici donné de sa pensée, est d'avoir rétabli les perspectives cosmiques du message chrétien.» ${ }^{20}$

Essa ação social e política de E. Mounier através da publicação da revista Esprit teve uma importante repercussão nos meios intelectuais cristãos. Reli recentemente a carta que Mounier escreveu a um de seus colaboradores em 14 de março de 1950, isto é poucos dias antes de seu falecimento. Eis a passagem em questão (que traduzi):

«Mas eu sei que não há paraíso sobre a terra. Creio perigosa a tendência de muitos dos nossos contemporâneos de querer encontrar um absoluto num regime político. Eu que sou cristão, e coloco a Igreja mais alto que todo regime político, eu sempre recusei os escritos que tratavam dos atos da Igreja apagando suas sombras. Tudo o que é humano tem sua face sombria e só é real, vivo, incarnado que por aí.» ${ }^{21}$

\footnotetext{
${ }^{19}$ Cf. Pe. Henrique de LIMA VAZ, Escritos de Filosofia- Problemas de Fronteira, Ed. Loyola, 1986, cap. V (« Pessoa e Sociedade : o Ensinamento de João XXIII »), p. 110.

${ }^{20}$ Cf. Emmanuel MOUNIER, «La Petite Peur du XXème Siècle », in CEuvres III, p. 402.

${ }^{21}$ Cf. E. MOUNIER, in Mounier et sa génération, Éd. du Seuil, 1956, p. 416, com uma apresentação de Mme Paulette Mounier-Leclercq.
} 
Essa reflexão ganha ainda em atualidade nos dias de hoje, com a dimensão enorme dos meios de comunicação e da publicidade, das fake news, onde as mentiras e os exagêros proliferam nos discursos políticos de quase todos países, e também com o que ficamos sabendo do comportamento de muitos padres no seio da Igreja.

Num contexto diferente, Pe. Vaz,- que havia sofrido bastante durante a ditatura- vai refletir sobre a situação política e sobre a dimensão ética. Na revista Síntese, ele publica em 1985 um artigo sobre "Democracia e Sociedade", onde observa:

"O desafio democrático com o qual a sociedade brasileira se vê presentemente confrontada impõe uma vigilante lucidez com respeito às relações corretas entre os dois polos que estruturam o campo de uma experiência viável: a idéia de democracia e a efetiva prática democrática." ${ }^{22}$

O que vivemos nos dias de hoje é uma grande crise da « prática democrática ", isto é dos regimes ditos democráticos, onde já existiam, no entanto, e, anteriormente, outras crises. Basta lembrar, por exemplo, a do racismo na « democracia » americana, na qual os « homens de cor » não tinham os mesmos direitos que os «brancos », e que ,embora podendo agora votar, continuam a sofrer muitas injustiças.

Mounier na observação que reproduzimos manifesta sua lucidez a respeito das instituições humanas, e também em relação ao conhecimento humano que é sempre parcial.

Esse caráter parcial dos nossos conhecimentos, do nosso saber, atinge todos nós, e não poupa de modo algum os cientistas, que são cada vez mais limitados pelas suas « especialidades », ignorando « descobertas » em outras áreas.

A marcha das descobertas científicas frequentemente desvia o pensamento da transcendência, ao contrário do que ocorreu com Teilhard de Chardin, ainda que ele tivesse sido de início maltratado pelas autoridades eclesiásticas. A frase que citamos acima onde Pe. Vaz alude a Teilhard por sua descoberta científica e a Mounier por sua ação social é bastante importante para uma a constitução de uma Antropologia Filosófica no mundo de hoje, ainda que a razão filosófica não possa ignorar que o saber da ciência e o agir político não dispensam um olhar crítico e a admissão de modificações ou de correções imprevisíveis.

Na sua coletânea Ontologia e Filosofia, há um capítulo IV - « Razão Vital e Ontologia » (Nota sobre Ortega)- , onde Pe.Vaz examina o obra de José Ortega y Gasset : "El tema de nuestro tiempo », obra que ele me fez descobrir. Numa das frases onde Pe. Vaz resume essa obra pode-se ler :

\footnotetext{
${ }^{22}$ Esse artigo de Pe. Vaz figura como o Anexo IV dos seus Escritos de Filosofia II- Ética e Cultura, Ed. Loyola, 1988, citação, p. 266.
} 
«O 'tema do nosso tempo' consistiria num esforço para religar as artérias partidas entre a 'razão' e a 'vida', e injetar assim na cultura o sangue de uma vitalidade que se esvaíra nos caminhos do racionalismo.»" ${ }^{23}$

A meu ver, Ortega y Gasset pressentiu que os " caminhos do racionalismo », ou seja do cientismo que impregna uma boa parte da nossa civilização se opõe à vida, não somente à vida humana mas à vida dos viventes (dos seres vivos), e separa portanto o ser racional, isto é o homem, das fontes de vida das quais ele depende.

No texto "Ciência e Ontologia da Natureza"- que segue o texto sobre o 'pensador' Ortega e que constitui o capítulo V de Ontologia e História -, Pe Vaz, ao refletir sobre o racionalismo da Modernidade e suas crises, escreve sobre o " eu » moderno e sua consciência enquanto sujeito pensante.

«O «eu» que define tal nível de consciência é essencialmente «construtor»: ele é o demiurgo do universo técnico».

E prosseguindo sua reflexão ele continua:

«[...] Segundo a confissão famosa da sexta parte do Discurso [Discours de la Méthode de Descartes], em lugar ' desta filosofia especulativa que se ensina nas escolas', ela nos irá tornar 'senhores e possuídores da natureza'..»

Logo depois dessa afirmação, Descartes acrescentava um pensamento (que eu resumo), segundo o qual essa 'senhoria' da natureza não acarretará apenas novos artefatos que farão que possamos gozar sem muito esforço dos frutos da terra, mas que contribuirá pricipalmente à conservação da saúde.

Assim se o pensamento de Descartes tinha primeiro a ver com a ciência, ele não negligenciava a técnica e a possibilidade de novos produtos, quando preconizava a necessidade para os homens de se tornarem como «senhores e possuídores da natureza ».

No que diz respeito a Mounier, falecido em 1950, e que não era cartesiano, importa também lembrar que há no texto intitulado "La Petite Peur du XXème siècle » (de 1949), uma defesa da técnica contra o "anti-tecnicismo" de alguns pensadores e de uma parte da sociedade francesa de seu tempo. Nesse texto, porém, ele não omite os horrores feitos pelos homens se servindo de objetos técnicos. Mas procura mostrar que tais horrores têm uma origem outra que a produção de objetos técnicos, mesmo se os homens podem fabricar objetos destruídores, como ele escreve na última página, onde menciona os horrores de Büchenwald e de Hiroshima. Horrores cometidos contra aqueles tidos por adversários e que não são vistos como " pessoas », mas como seres inferiores e como inimigos a exterminar...

${ }^{23}$ Cf. Pe. Henrique de LIMA VAZ, " Razão Vital e Ontologia" in Ontologia e História, Ed. Loyola, 2001, 94.

${ }^{24}$ Cf. Pe. Henrique de LIMA VAZ, "Ciência e Ontologia da Natureza, in Ontologia e História, p. 115. 
Essas ações monstruosas não condenam a técnica enquanto tal. Elas têm, sim, a ver com a questão do Mal, do desconhecimento da pessoa em todo ser humano, e portanto da prevalência da mentira e das ilusões. [Questões que não podemos abordar aqui.] Mounier esperava que o bom lado da técnica prevaleceria, melhorando a vida humana, facilitando uma série de ações e o contacto entre os homens.

Ora, hoje estamos numa outra época que a de Mounier, época decisiva para a vida na Terra, em que não é mais possível se ignorar que uma boa parte dos produtos técnicos industriais podem acarretar grandes malefícios para o nossa planeta, na medida em que aumentam, por exemplo, o aquecimento climático e tudo o que dele decorre.

Mas há ainda um outro aspecto que não pode ser negligenciado nos tempos de hoje e que Descartes jamais poderia ter imaginado quando pensava nas boas 'aplicações' da ciência.

Trata-se da fabricação, em particular, de produtos químicos (pesticidas, inseticidas) que estão destruindo boa parte da natureza como «meio ambiente» São produtos usados voluntariamente, e que são fontes de consideráveis lucros financeiros. Pode-se até dizer que Ortega y Gasset ao denunciar os racionalismos como opostos à ordem vital, tinha pressentido algo que hoje está vigorando numa civilização como a nossa : a ameaça que pesa sobre nosso ambiente vital por parte dos 'racionalismos' (ou dos cientismos parciais) que nutrem e estão na base de indústrias nocivas à vida na Terra.

Tais problemas nos remetem ao que se deve entender quando se afirma a transcendência do homem sobre a natureza. Na sua obra Le Personnalisme, Mounier emprega a seguinte expressão : "A Pessoa transcende a natureza $»^{25}$; ele o faz depois de considerar «A existência incorporada », já que o homem é " tout entier corps et tout entier esprit ». Daí pode se inferir que a transcendência do homem sobre a natureza - e ele é um 'ser natural' que por 'seu corpo faz parte da natureza'- tem a ver com a capacidade do espírito humano de se voltar para " além do mundo », para o que chamamos de sobrenatural : o divino que ultrapassa a natureza.

Ao abordar a questão da transcendência em «Cristianismo e Consciência Histórica », (que constitui o capítulo VII de Ontologia e História), Pe Vaz ao abordar a questão moderna da subjetividade e da visão cristã, vai afirmar :

« Esta [a visão cristã], com efeito tem seu centro numa aguda compreensão da subjetividade como radical transcendência sobre a 'ordem' natural do mundo e como liberdade empenhada num destino histórico. $»^{26}$

\footnotetext{
${ }^{25}$ Cf. E. MOUNIER, «Le Personnalisme», (1949), in CEuvres III, Éditions du Seuil, 1962, p. 442.

${ }^{26}$ Cf. Pe. Henrique de LIMA VAZ, in "Cristianismo e Consciência Histórica" in Ontologia e História, Parte II, capítulo VII, p. 166.
} 
Mais adiante, e depois de um desenvolvimento importante sobre à compreensão da História, no nosso mundo, ele escreve ainda sobre " uma transcendência ativa do homem sobre o mundo [...]», acrescentando em seguida :

«Ora, a inspiração mais original do 'personalismo' bíblico-cristão, e que o contradistingue do 'naturalismo' helênico, reside precisamente na aguda visão da transcendência do homem sobre a natureza, na afirmação do seu empenho histórico num plano de decisões e acontecimentos - a história da salvação - irredutível ao mundo das conexões 'naturais'.» ${ }^{27}$

Embora não possamos nos estender sobre toda a reflexão do Pe Vaz nesse seu texto sobre o naturalismo científico e a consciência histórica, importa porém interrogar a ambivalência do que se entende por «transcendência do homem sobre a natureza».

A questão mais que premente que está se colocando nos dias de hoje é justamente a da dominação da natureza pelo homem, donde vem decorrendo a destruição do meio ambiente, isto é da natureza, e isso pelas indústrias do homem, pelo seu agir na Terra. Destruições que comprometem a vida dos seres vivos : vegetais, animais e dos seres humanos eles próprios.

Em 2020, fazem cinco anos que temos a Encíclica Laudato Si do Papa Francisco encorajando as iniciativas ecológicas. Mas convém ainda sublinhar que o Papa Francisco agora reuniu, no Vaticano (em 3 de setembro de 2020), um grupo de franceses empenhados na ecologia, ele próprio evocando diante dos presentes - dentre os quais Monsenhor Eric de Moulins-Beaufort e Gaël Giraud S.J. - uma necessária «conversão ecológica».

O que me parece também imprescindível é a leitura de um livro da biologista americana, Rachel Carson (1907-1964), livro intitulado Silent Spring e publicado, em 1962. Livro traduzido em francês [Printemps silencieux], e hoje (em 2020) republicado na França, e que está cada vez mais na ordem do dia para aqueles que defendem a sobrevivência dos seres vivos no nosso planeta.

Um ponto crucial dessa obra é seu levantamento do que já estava ocorrendo no seu país (os Estados Unidos) e sua denúncia da indústria dos produtos químicos de síntese (artificiais) que acarretam destruições incríveis do solo, da vegetação, dos animais e também da saúde e da vida dos homens. E isso porque como ela dirá : «na natureza tudo é ligado» (p.96).

Rachel Carson constatou o que estava acontecendo em várias áreas de seu país (e que hoje não poupa nenhum) devido ao uso de pesticidas, inseticidas, herbecidas, fungicidas. Ela faz um repertório realmente espantoso

${ }^{27}$ Cf. Ibidem, p. 175. 
dos desastres provocados por esses produtos e de suas pulverizações. E isso no horizonte da ilusão do ser humano quando acredita poder reinar sobre a natureza.

Não sendo possível comentar e analisar os múltiplos aspectos da bio-diversidade que ela nos faz descobrir, limitar-me-ei a citar a breve reflexão que se encontra no início do capítulo 7 de Silent Spring:

«À medida que ele progride rumo a seu objetivo anunciado de conquista da natureza, o homem deixa atrás dele uma impressionante trajetória de destruições afetando a Terra onde habitam ele e os seres que partilham com ele essa morada. ${ }^{28}$

Temos que constatar que nem Mounier, nem mesmo Pe. Vaz tiveram consciência do que já estava ocorrendo com a Terra enquanto 'a casa comum' dos seres vivos - e portanto da vida do homem enquanto ser vivo -, quando se referiam à " transcendência do homem sobre a natureza ».

Mesmo que essa " transcendência » possa ser entendida num sentido outro que o da dominação da natureza, ou seja num sentido espiritual que leva o ser humano a se despojar, na medida do possível, dos instintos e apetites naturais, a afirmação da transcendência do homem sobre a natureza se presta a muitas interpretações errôneas, e alimentam as mentiras que conduzem ao desastre ecológico.

Estas questões nos levam também a encarar o pensamento humano como não devendo se fixar uma vez por todas, mas como exigindo do pensador, do filósofo, uma reflexão, um questionamento que não podem jamais ser concluídos. O pensamento filosófico requer uma abertura, abertura voltada para a complexidade do que é justo e verdadeiro. Afirmação que Pe. Vaz e E. Mounier não teriam desmentido.

Endereço da Autora:

57 rue Lhomond

75005 Paris - França

e-mail : <maria.villela.petit@gmail.com>

${ }^{28}$ Cf. Rachel CARSON, Printemps silencieux [Silent Srping], com uma Introduction Al Gore, trad. fr. de Jean-François Gravand, révisée par Baptiste Lanaspeze, éd. Wildproject, 2020, p. 129. A obra Silent Spring se encontra também, no Brasil traduzida em português [A Primavera silenciosa]. Cf. Editora Gaia, São Paulo, 2015. O trecho que citamos na nossa tradução se encontra na pg. 85, da edição brasileira, como ficamos sabendo graças a Emília de Moraes. 